\title{
https://doi.org/10.46813/2021-131-009 \\ MODELLING OF RADIO-FREQUENCY WALL CONDITIONING IN SHORT PULSES IN A STELLARATOR
}

\author{
Yu.S. Kulyk ${ }^{1}$, V.E. Moiseenko ${ }^{1}$, T. Wauters ${ }^{2}$, A.I. Lyssoivan ${ }^{2}$ \\ ${ }^{1}$ Institute of Plasma Physics, National Science Center "Kharkov Institute of Physics and \\ Technology", Kharkiv, Ukraine; \\ ${ }^{2}$ Laboratory for Plasma Physics - ERM/KMS, Association EURATOM-BELGIAN STATE, \\ 1000 Brussels, Belgium
}

\begin{abstract}
Results of numerical modelling of electron cyclotron (EC) short pulse wall conditioning discharge are presented. The analysis carried out with the usage of a self-consistent model that simulates radio-frequency (RF) plasma production in stellarator type machines in the ion cyclotron and EC frequency ranges. The discussion of the results of the calculations is presented.
\end{abstract}

PACS: 52.50.Qt, 52.55.Hc

\section{INTRODUCTION}

The hydrogen wall conditioning aiming for producing hydrogen atoms was practiced at many fusion devices with truly positive results [1]. The mechanism of wall conditioning consists of the interaction of the plasma ions and neutral hydrogen atoms with the wall surfaces in which volatile substances are formed with a certain probability. They can be pumped out from the vacuum chamber.

In a wall conditioning discharge, it is important that the plasma density is not high in order to decrease the probability of ionization of desorbed impurities. The scenario which meets this requirement was proposed in [2]. It is based on the slow wave excitation by the small antenna of a special design. The advantage of this scenario is the low frequency that facilitates generator and antenna design and lowers the costs of the radiofrequency (RF) equipment. On the other hand, a high steady magnetic field is necessary for this scenario. This is provided in machines with cryogenic magnetic coils.

The 1D code [3] simulating RF plasma production in stellarator type machines in the ion cyclotron range of frequencies was used to study this discharge. For a successful start-up of the discharge, it is necessary to provide overlapping of the slow wave global resonances. Following paper [2], this is difficult to provide for low $\mathrm{k}_{\mid}$resonances. To excite the slow wave with high $\mathrm{k}_{\text {, }}$ a T-shaped antenna was used instead of the single frame antenna [4]. This suppresses the excitation of long-wave modes. For the reason of well charged particle confinement in a stellarator, the continuous discharge with RF power about $10 \mathrm{~kW}$ produces dense plasma with low temperature and full ionization. This is not beneficial for the generation of neutral hydrogen atoms which are necessary for wall conditioning [3]. Calculations show that pulsed discharge is more efficient in this. At the plasma build-up stage, the atoms are generated mainly owing to the dissociation of hydrogen molecules by electron impact. When the RF power is off the dissociative recombination of molecular ions with electrons comes to play. The recombination of hydrogen ions at divertor plates also contributes, but with a lower rate.

The idea was to use a pulsed discharge with high electron temperature during the pulse. It is known that, on the one hand, ECRH is well absorbed only at high temperatures, and on the other hand, a low-temperature discharge is required for the efficient production of hydrogen atoms. For this reason, ECRH should be used in a short-pulse regime. During the pulse, the plasma density grows up since the plasma production rate exceeds plasma losses. After the end of the pulse, electrons are quickly cooled due to energy losses in collisions with neutral gas. In the pause between pulses, the plasma decays owing to the recombination of cold electrons and ions.

As a prototype for the new self-consistent model, the models for atomic gas [5] and for molecular hydrogen [3] are used, which are developed by the research group earlier.

The developed earlier model for atomic hydrogen can describe the final stage of plasma production. In the model for molecular hydrogen, only electron-molecule hydrogen collisions are accounted for. The particle balance is determined by the ionization of the hydrogen molecule. This model is suitable for plasma with a low ionization degree.

There is a need for a model that incorporated all the collision processes and is valid at all stages of plasma production in a stellarator. Note here that the lower dimensionality 0D model for all sorts of hydrogen and helium is described in [6]. That model was developed to a 1D tokamak model [7].

A recently developed model is for stellarators and includes the system of the particle and energy balance equations for the electrons and the boundary problem for Maxwell's equations. A new feature of the newly developed model is an account of molecular ions, $\mathrm{H}_{2}{ }^{+}$, and $\mathrm{H}_{3}{ }^{+}$, in the particle balance equations [8]. The model uses neoclassical diffusion, turbulent transport, and elementary atomic and molecular collision processes. In the balance of neutral gas, the hydrogen 
retention and recombination at the wall surface are taken into account.

On the base of the model, a one-dimensional numerical code is developed. In addition to the RF module, the numerical code is supplemented with a module for electron-cyclotron heating $(\mathrm{ECH})$. A new module that models second harmonic ECH in case of weak wave damping is created and incorporated into the code. The code can work using either RF or EC modules.

The ECRH module takes into account that power deposition is proportional to the plasma density. Besides, it is proportional to the width of the EC zone which is narrow when the electron temperature is low. The power deposition formula reads:

$$
p_{E C R H}=\frac{p_{0}}{V_{V}} \exp \left(-\left(r / r_{p l}\right)^{2}\right)\left(n_{e} / n_{0}\right) / 2,
$$

where $p_{E C R H}$ is the power deposition density, the quantity indexed with zero is the normalizing constant, $V_{V}$ is the vacuum chamber volume, $r_{p l}$ is the characteristic radius of power deposition, $n_{e}$ is the plasma density, $n_{0}$ is the initial density of neutral gas.

A scenario of short-pulse ECRH discharges series in hydrogen had been proposed for wall conditioning in W7-X. At the beginning of the W7-X experimental campaign OP1.2b, successful discharges were produced in accordance with the proposed scenario, with a single and four ECRH pulses start-ups with the use of a preionization plasma [9].

The recent model for discharges in molecular hydrogen was improved. In the previous version of the model, the distribution of molecules was considered uniform over the entire vacuum chamber volume. But this assumption is not true for discharges with highly localized power input, since the neutral gas becomes non-uniform inside the plasma column in this case.

In the updated model, we consider the distribution of atomic gas to be uniform since atomic gas has high (Frank-Condon) energies. For a molecular gas, we use the following transport equations:

$$
\begin{aligned}
& \frac{\partial n_{H_{2}}}{\partial t}-\frac{1}{r} \frac{\partial}{\partial r}(r G)=I_{p u f f}+C_{H} \frac{S}{2 V_{V}}<\mathrm{v}_{H}>n_{H}- \\
& -\left\langle\sigma_{i, H_{2}} \mathrm{v}\right\rangle n_{e} n_{H_{2}}-\left\langle\sigma_{d, H_{2}} \mathrm{v}\right\rangle n_{e} n_{H_{2}}-\left\langle\sigma_{t r, H_{2}^{+}} \mathrm{v}\right\rangle n_{H_{2}} n_{H_{2}^{+}}, \\
& \frac{\partial G}{\partial t}-v_{T H}^{2} \frac{1}{r} \frac{\partial}{\partial r}\left(r n_{H_{2}}\right)=-\left\langle\sigma_{i, H_{2}} \mathrm{v}\right\rangle n_{e} G- \\
& -\left\langle\sigma_{d, H_{2}} \mathrm{v}\right\rangle n_{e} G-\left\langle\sigma_{t r, H_{2}^{+}} \mathrm{v}\right\rangle n_{H_{2}^{+}} G-v_{e f f} G,
\end{aligned}
$$

where $n_{H}, n_{H 2}$ are the densities of the atom and molecule hydrogen, $n_{\mathrm{H}+}, n_{\mathrm{H} 2+}$ are the densities of atomic and molecular hydrogen ions, $G$ is the particle flux, $\left\langle\sigma_{i, H_{2}} \mathrm{v}\right\rangle$ is the ionization rate, $\left\langle\sigma_{d, H_{2}} \mathrm{v}\right\rangle$ is the electron impact dissociation rate, $\left\langle\sigma_{t r, H_{2}^{+}} \mathrm{v}\right\rangle$ is the transformation rate, $I_{p u f f}$ is the neutral gas puff rate, $C_{H}$ is the coefficient of reflection of atomic hydrogen from the chamber wall, $v_{\text {eff }}$ is the deceleration coefficient.

In this paper, results of numerical simulation of RF wall conditioning discharges in $\mathrm{W} 7-\mathrm{X}$ stellarator with the self-consistent model are presented.

\section{NUMERICAL RESULTS OF MODELLING}

Numerical simulation results are presented in Figs. 1-15. The following parameters of numerical calculations are chosen: the major radius of the torus is $R=3.5 \cdot 10^{2} \mathrm{~cm}$, the characteristic radius of power deposition is $r_{p l}=15 \mathrm{~cm}$, the radius of the metallic wall is $a=60 \mathrm{~cm}$, the initial plasma density is $n_{e O}=1 \cdot 10^{8} \mathrm{~cm}^{-3}$, the initial density of the neutral gas is $n_{0}=2 \cdot 10^{12} \mathrm{~cm}^{-3}$. In the numerical experiments, the power deposition value is varied in the following range: $p_{0}=1 \cdot 10^{7} \ldots 2.3 \cdot 10^{7} \mathrm{~W}$ that corresponds to total ECRH power below $1 \mathrm{MW}$.

Fig. 1 shows a comparison of the time evolution of electron density with experimental data for $3 \mathrm{~ms}$ ECRH pulse. We see that the calculated curve is close to the experimental one.

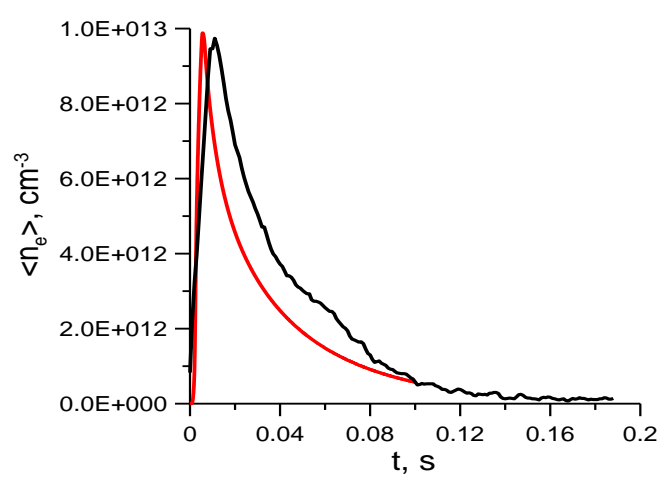

Fig. 1. Time evolution of electron density for the ECRH discharges at W7-X (black curve-experimental datas, red-numerical datas)

Some difference between experiment and numerical simulation can be explained by the fact that some amount of fast electrons is produced in the experiment. And the presence of these electrons causes further ionization. The model does not take them into account.

The following figures demonstrate the influence of calculation parameters on the calculation results. Hereinafter, the basic variant of numerical calculations is marked in red.

Figs. 2-8 display calculated time evolution of electron density, electron temperature, $\mathrm{H}^{+}, \mathrm{H}_{2}^{+}, \mathrm{H}_{3}^{+}, \mathrm{H}_{0}$, and $\mathrm{H}_{2}$ densities for the ECRH discharges at W7-X for different ECRH power values.

In Fig. 2 we see that all curves up to the second millisecond behave similarly. This suggests that when the power changes, the ionization rate remains almost the same.

That is, the ionization rate weakly depends on power. That means that the electron temperature is high, and it has the values at which the dependence of the ionization cross section on temperature is weak. And, if so, then we have almost the same ionization rate at different temperatures and, therefore, at different power values.

If there is not enough power to heat the electrons to high temperatures (light blue curve), a low density is created only during the pulse time and the temperature of the electrons decreases rapidly after. The density value in this case is noticeably small. 


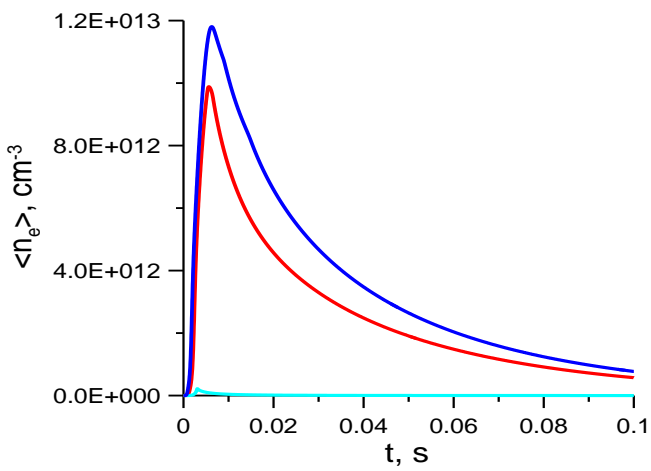

Fig. 2. Time evolution of electron density for the ECRH discharges at W7-X for different power deposition values $\left(p_{0}=1 \cdot 10^{7} \mathrm{~W}\right.$ (light blue curve), $p_{0}=1.5 \cdot 10^{7} \mathrm{~W}(\mathrm{red}), p_{0}=2.3 \cdot 10^{7} \mathrm{~W}($ blue $)$ )

Fig. 3 shows the average temperature. Since the discharge is much localized, the plasma dimensions generally correspond to the localization of microwave radiation. The plasma column is narrow, and averaging occurs over the entire volume. Therefore, the average temperatures are significantly lower than the peak temperatures at the centre.

The observed pattern corresponds to what is seen in Fig. 2. As long as the temperature keeps high values, the ionization process takes place.

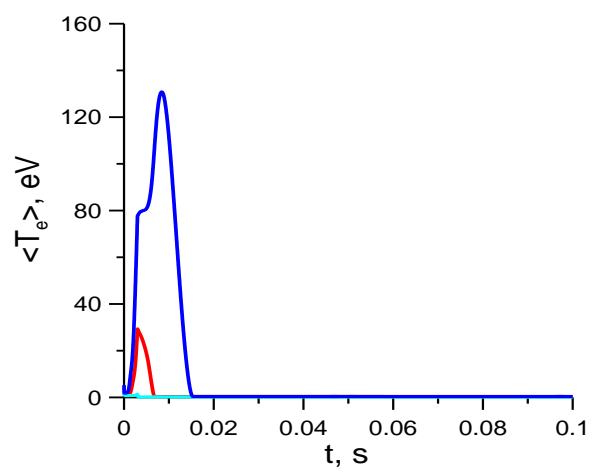

Fig. 3. Time evolution of electron temperature for the ECRH discharges at W7-X for different power deposition values ( $p_{0}=1 \cdot 10^{7} \mathrm{~W}$ (light blue curve), $p_{0}=1.5 \cdot 10^{7} \mathrm{~W}(\mathrm{red}), p_{0}=2.3 \cdot 10^{7} \mathrm{~W}($ blue $\left.)\right)$

In Fig. 4 the picture is similar to Fig. 2. The rates of $\mathrm{H}^{+}$formation are essentially the same as the rates of electron production. $\mathrm{H}^{+}$is the main ion that is born. This is due to the high temperature. At a high electron temperature, the process of dissociative ionization is very efficient, and $\mathrm{H}^{+}$is generated directly from $\mathrm{H}_{2}$.

Fig. 5 shows that not much $\mathrm{H}_{2}{ }^{+}$is produced because there is a competing process, dissociative ionization of $\mathrm{H}_{2}^{+}$. In addition, when $\mathrm{H}_{2}{ }^{+}$is produced, it either ionizes or dissociates. These are very intensive processes, so $\mathrm{H}_{2}{ }^{+}$does play a transient role in this case.

$\mathrm{H}_{3}{ }^{+}$(see Fig. 6) is formed from the collision of $\mathrm{H}_{2}{ }^{+}$ and $\mathrm{H}_{2}$, and this is the only process that produces it. This process takes place without the participation of electrons. The process is slow due to the small cross section. As a result of the fact that everything happens quickly in our case, $\mathrm{H}_{3}^{+}$is formed in very small concentrations.

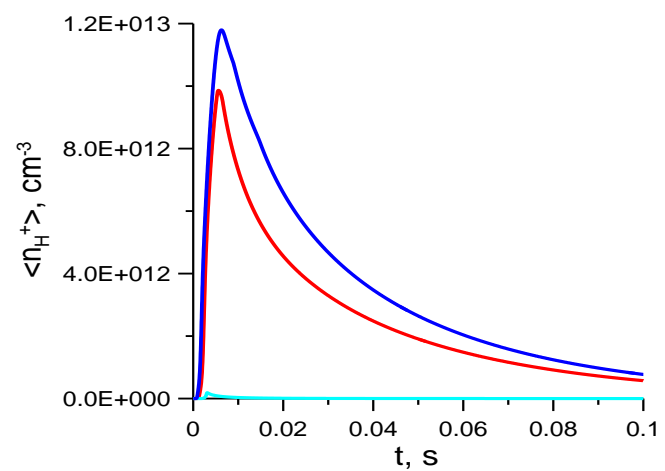

Fig. 4. Time evolution of $\mathrm{H}^{+}$density for the ECRH discharges at $W 7-X$ for different power deposition values $\left(p_{0}=1 \cdot 10^{7} \mathrm{~W}\right.$ (light blue curve), $p_{0}=1.5 \cdot 10^{7} \mathrm{~W}(\mathrm{red}), p_{0}=2.3 \cdot 10^{7} \mathrm{~W}$ (blue) $)$

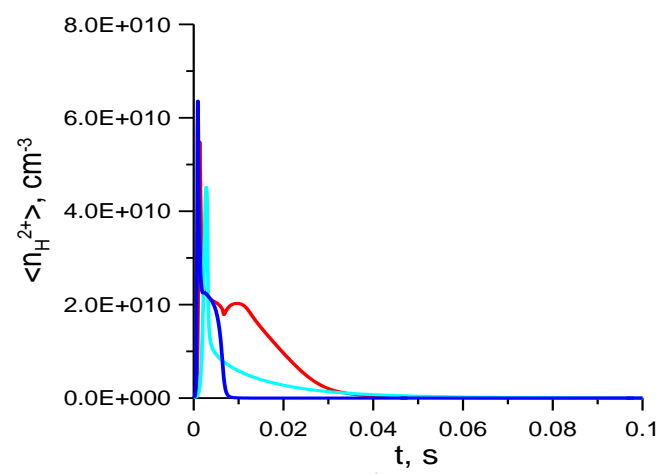

Fig. 5. Time evolution of $\mathrm{H}_{2}{ }^{+}$density for the ECRH discharges at W7-X for different power deposition values $\left(p_{0}=1 \cdot 10^{7} \mathrm{~W}\right.$ (light blue curve), $p_{0}=1.5 \cdot 10^{7} \mathrm{~W}(\mathrm{red}), p_{0}=2.3 \cdot 10^{7} \mathrm{~W}($ blue $\left.)\right)$

Due to the fact that in the case of a higher power (blue curve) the gas burns out quickly, a small amount of $\mathrm{H}_{3}{ }^{+}$is produced.

In the case with the lowest power (light blue curve), $\mathrm{H}_{3}{ }^{+}$is also produced, but the decrease in the density level is due to the fact that the discharge itself has a low density.

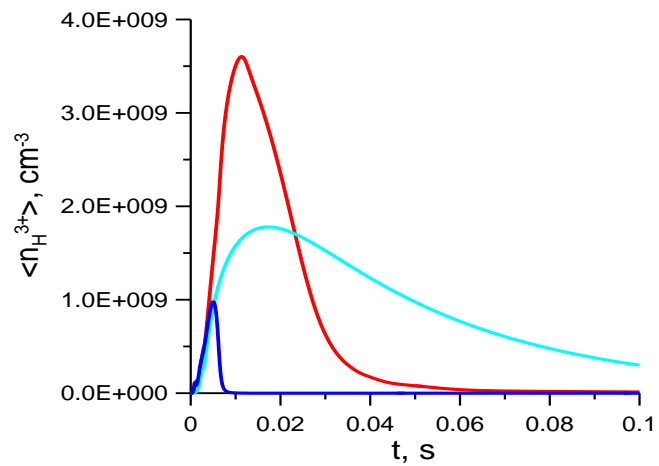

Fig. 6. Time evolution of $\mathrm{H}_{3}{ }^{+}$density for the ECRH discharges at W7-X for different power deposition values $\left(p_{0}=1 \cdot 10^{7} \mathrm{~W}\right.$ (light blue curve), $p_{0}=1.5 \cdot 10^{7} \mathrm{~W}(\mathrm{red}), p_{0}=2.3 \cdot 10^{7} \mathrm{~W}($ blue $\left.)\right)$

In Fig. 7 at the beginning, we observe a rapid production of hydrogen, but later this production is inferior to the production of hydrogen in the process of recombination. Recombination makes a major contribution to the hydrogen atom generation process. 
We also observe some delay, which is different for each case. And this delay corresponds to the moment when the electron temperature takes on low values. After the decrease of the electron temperature, the recombination process begins, and, accordingly, the density decreases.

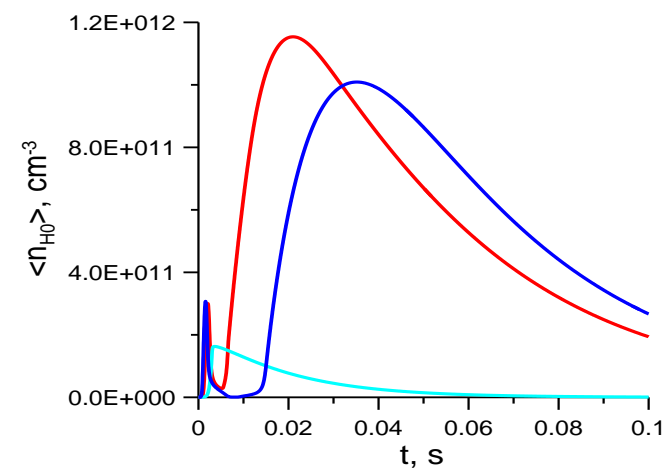

Fig. 7. Time evolution of $\mathrm{H}_{0}$ density for the ECRH discharges at $W 7-X$ for different power deposition values $\left(p_{0}=1 \cdot 10^{7} \mathrm{~W}\right.$ (light blue curve), $p_{0}=1.5 \cdot 10^{7} \mathrm{~W}(\mathrm{red}), p_{0}=2.3 \cdot 10^{7} \mathrm{~W}$ (blue) $)$

Fig. 8 shows gas burn out. For each power value, the amount of burned out gas is different. The higher the power, the more the gas burned out.

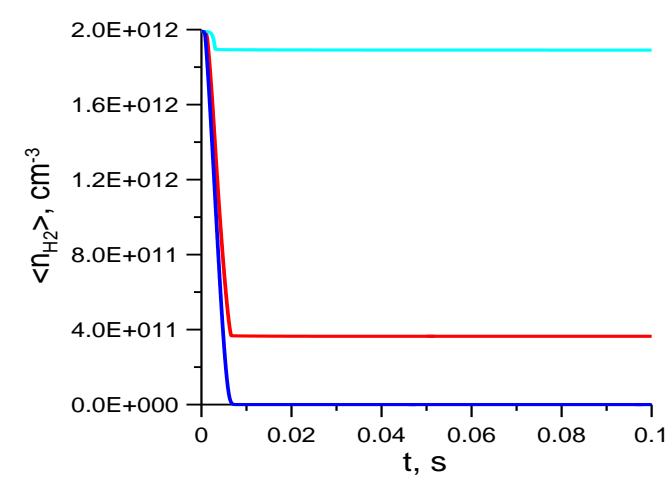

Fig. 8. Time evolution of $\mathrm{H}_{2}$ density for the ECRH discharges at $W 7-X$ for different power deposition values $\left(p_{0}=1 \cdot 10^{7} \mathrm{~W}\right.$ (light blue curve), $p_{0}=1.5 \cdot 10^{7} \mathrm{~W}(\mathrm{red}), p_{0}=2.3 \cdot 10^{7} \mathrm{~W}$ (blue) $)$

Figs. 9-13 display the radial profiles of electron density, electron temperature, $\mathrm{H}^{+}, \mathrm{H}_{2}{ }^{+}$, and $\mathrm{H}_{2}$ densities in the time moment $t=3.5 \mathrm{~ms}$ for different ECRH power values.

In Fig. 9 we see that the density profiles are peaked. In the photo of the plasma column in $\mathrm{H}$-alpha rays [9], we can see that the plasma column is rather narrow.

The difference in the curves can be explained as follows. Since the power deposition is inhomogeneous along the radius, the ionization rate is different at different points of the radius. At the centre of the plasma column, the ionization rate is higher, and at the periphery, the ionization rate is lower. Plasma is produced only when the ionization rate exceeds the loss rate. At the periphery of the plasma column, starting from a certain point, the ionization rate decreases, while the loss rate is approximately the same everywhere. That is, there is a point where the ionization rate and the loss rate become comparable. We see this point in Fig. 9. For the light blue curve, it is about $15 \mathrm{~cm}$, for the red one $-33 \mathrm{~cm}$, for the blue one $-40 \mathrm{~cm}$. When the radius values are higher than these values, no plasma is produced. But, if the total power is increased, this point shifts along the radius in the direction of increase.

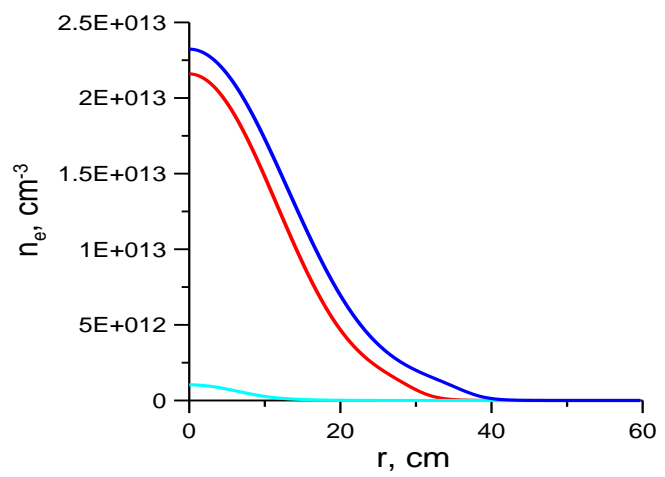

Fig. 9. Radial profile of electron density in the time moment $t=3.5 \mathrm{~ms}$ for different power deposition values $\left(p_{0}=1 \cdot 10^{7} \mathrm{~W}\right.$ (light blue curve), $p_{0}=1.5 \cdot 10^{7} \mathrm{~W}(\mathrm{red}), p_{0}=2.3 \cdot 10^{7} \mathrm{~W}($ blue $\left.)\right)$

The radial electron temperature profiles (see Fig. 10) are also peaked. At a higher power value, we observe that the electron temperature profile is wider and the electron temperature value is higher.

Fig. 11 shows a picture similar to Fig. 9.

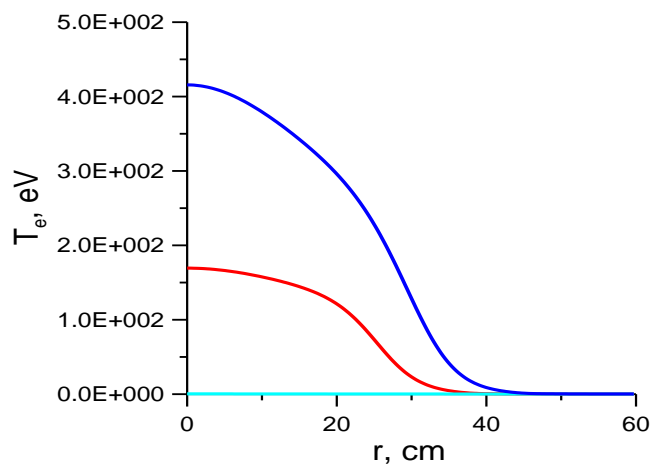

Fig. 10. Radial profile of electron temperature in the time moment $t=3.5 \mathrm{~ms}$ for different power deposition values $\left(p_{0}=1 \cdot 10^{7} \mathrm{~W}\right.$ (light blue curve), $p_{0}=1.5 \cdot 10^{7} \mathrm{~W}($ red $), p_{0}=2.3 \cdot 10^{7} \mathrm{~W}($ blue $\left.)\right)$

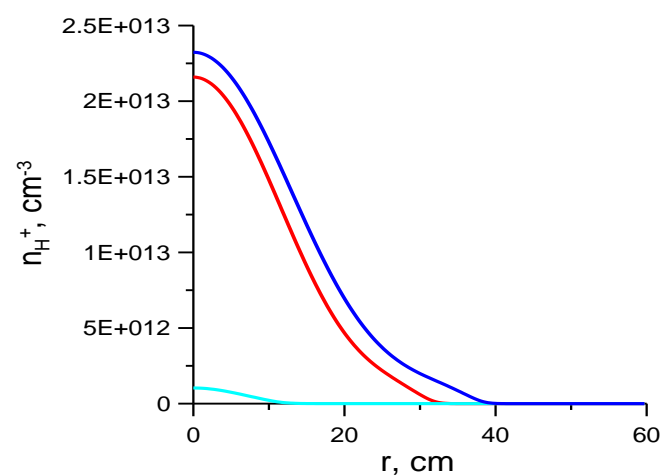

Fig. 11. Radial profile of $\mathrm{H}^{+}$in the time moment $t=3.5 \mathrm{~ms}$ for different power deposition values $\left(p_{0}=1 \cdot 10^{7} \mathrm{~W}\right.$ (light blue curve $), p_{0}=1.5 \cdot 10^{7} \mathrm{~W}(\mathrm{red})$, $p_{0}=2.3 \cdot 10^{7} \mathrm{~W}$ (blue))

We observe $\mathrm{H}_{2}^{+}$only at the edge of the plasma column (see Fig. 12), where the electron temperature is low. Inside the plasma column, at high electron 
temperatures, $\mathrm{H}_{2}{ }^{+}$quickly burns out. Where the electron temperature values were lower, the $\mathrm{H}_{2}{ }^{+}$did not have time to burn out.

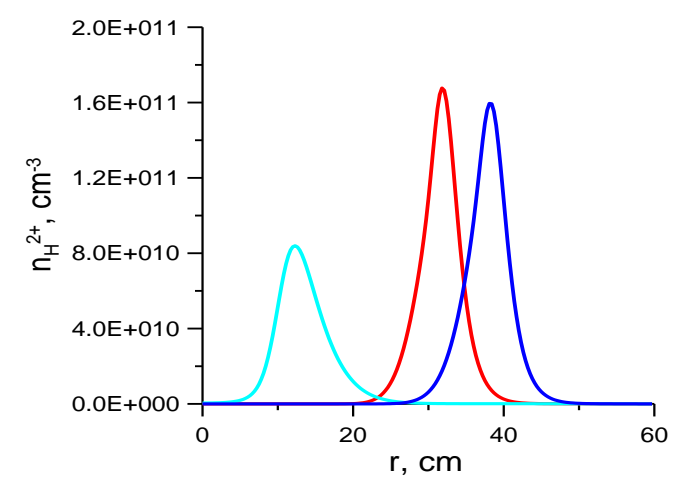

Fig. 12. Radial profile of $\mathrm{H}_{2}{ }^{+}$in the time moment $t=3.5 \mathrm{~ms}$ for different power deposition values $\left(p_{0}=1 \cdot 10^{7} \mathrm{~W}\right.$ (light blue curve), $p_{0}=1.5 \cdot 10^{7} \mathrm{~W}(\mathrm{red}), p_{0}=2.3 \cdot 10^{7} \mathrm{~W}($ blue $\left.)\right)$

Neutral gas entering the plasma column is ionized. Where there is plasma, there is no neutral gas in the time moment chosen (see Fig. 13). In the case of the lowest power (light blue curve), the amount of neutral gas dropped very slightly, as a result of the fact that a small amount of plasma was formed.

The penetration depth of the neutral gas is always small. It means the free path is short. As a result, the neutral gas ionizes at the plasma boundary, which we see in the two considered cases (red and blue curves). In the case of the lowest power (light blue curve), this power is not sufficient to burn out gas from the centre of the plasma column.

It should also be noted that such a discharge with a peaked power deposition cannot be described using a model in which the distribution of molecules is uniform over the entire plasma cross section. Fig. 13 shows how non-uniform the neutral gas distribution is and how important it is to take account of the non-uniform burn out.

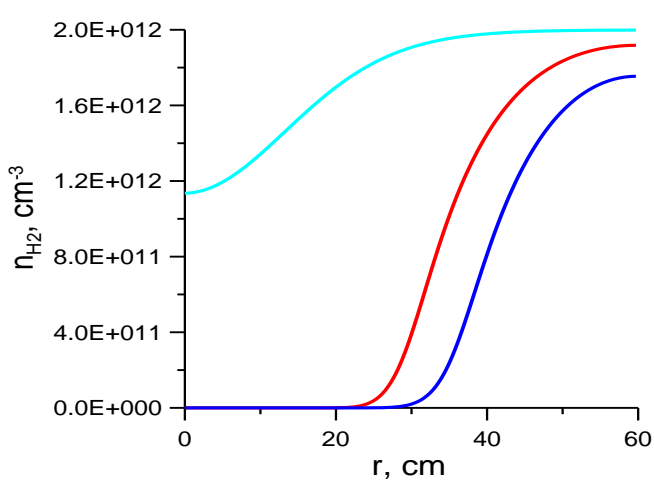

Fig. 13. Radial profile of $\mathrm{H}_{2}$ in the time moment $t=3.5 \mathrm{~ms}$ for different power deposition values $\left(p_{0}=1 \cdot 10^{7} \mathrm{~W}\right.$ (light blue curve),

$p_{0}=1.5 \cdot 10^{7} \mathrm{~W}(\mathrm{red}), p_{0}=2.3 \cdot 10^{7} \mathrm{~W}$ (blue) $)$

The amount of atoms produced during one pulse was also calculated for a series of numerical calculations. For the basic variant $\left(p_{0}=1.5 \cdot 10^{7} \mathrm{~W}\right)$ this parameter is $1.5 \cdot 10^{18}$. For the case with lower power value $\left(p_{0}=1 \cdot 10^{7} \mathrm{~W}\right): 8.7 \cdot 10^{16}$, for higher power value $\left(p_{0}=2.3 \cdot 10^{7} \mathrm{~W}\right): 1.4 \cdot 10^{18}$. The calculations have shown that the maximum generation of neutral atoms is observed for the basic variant. The minimum generation of neutral atoms is observed at the minimum ECRH power value.

The calculation results for single pulses were presented above. The purpose of these pulses is to produce hydrogen atoms. To provide continuity of these processes, it is necessary to use a series of such pulses. The parameters of the pulses remain the same, and the ECRH pulse is periodic with duty cycle $0.1 \mathrm{~s}$.

In Figs. 14,15 the result of such calculations is presented. We see that at the initial moment the pulses are different in amplitude, and then they quickly enter the stationary mode. A good level of production of hydrogen atoms in a quasi-steady state is achieved in this mode. In each individual pulse, physical processes are very similar to those processes that occur in a single pulse. And this can serve as a scenario for wall conditioning in $\mathrm{W} 7-\mathrm{X}$.

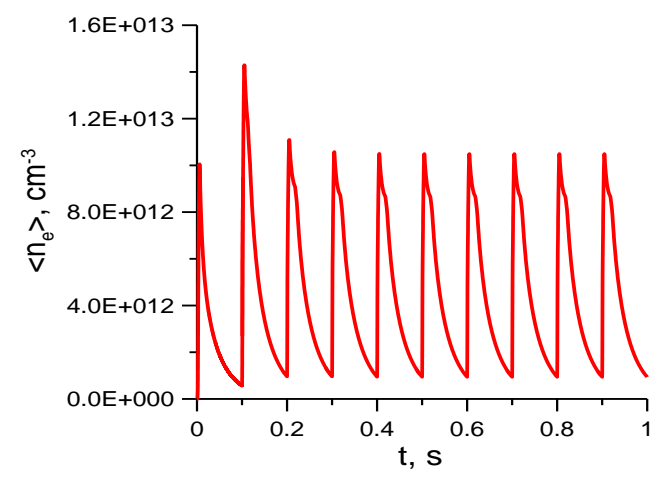

Fig. 14. Time evolution of electron density for series of pulses for the ECRH discharges at W7-X

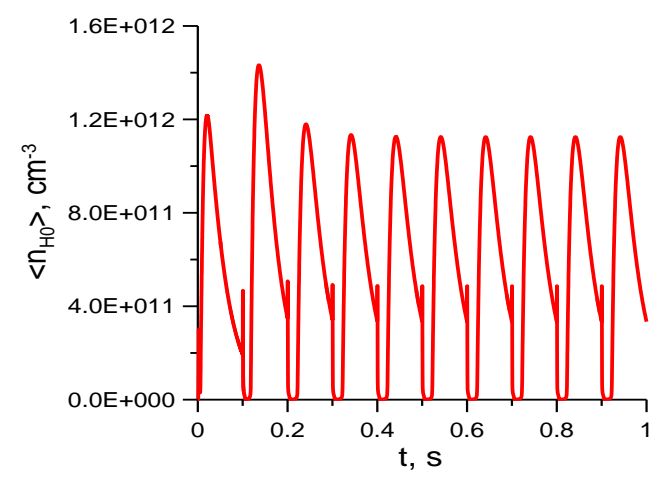

Fig. 15. Time evolution of $\mathrm{H}_{0}$ density for series of pulses for the ECRH discharges at W7-X

\section{CONCLUSIONS}

Results of numerical modelling of electron cyclotron short pulse wall conditioning discharge are presented.

The analysis carried out with the usage of a selfconsistent model that simulates (RF) plasma production in stellarator type machines in the ion cyclotron and EC frequency ranges.

The calculation results for single pulses were presented. The purpose of these pulses is to produce hydrogen atoms and their effect on the wall conditioning in a stellarator. With certain accuracy, 
the calculation reproduces the experimental pulse. The calculations indicate that the most hydrogen generation takes place at the plasma decay stage when the low electron temperature stimulates recombination. To provide the continuity of atomic hydrogen generation, it is necessary to use a long series of such pulses. The result of modelling such a regime is presented also. The numerical calculations have shown that this regime can serve as a base of a scenario for wall conditioning in W7-X.

\section{ACKNOWLEDGEMENTS}

This work has been carried out within the framework of the EUROfusion Consortium and has received funding from the Euratom research and training programme 2014-2018 and 2019-2020 under Grant Agreement No. 633053. The views and opinions expressed herein do not necessarily reflect those of the European Commission.

This work also received funding from National Academy of Sciences of Ukraine (grants P-3-22 and A-5-20).

\section{REFERENCES}

1. A.V. Lozin, V.E. Moiseenko, L.I. Grigor'eva, et al. Cleaning of inner vacuum surfaces in the Uragan-3M facility by radio-frequency discharges // Plasma Physics Reports. 2013, v. 39, № 8, p. 624-631.

2. V.E. Moiseenko, A.V. Lozin, V.V. Chechkin, et al. VHF discharges for wall conditioning at the Uragan-2M torsatron // Nucl. Fusion. 2014, v. 54, № 3, p. 033009.
3. Yu.S. Kulyk, V.E. Moiseenko, T. Wauters, A.I. Lyssoivan. Radio-Frequency Wall Conditioning for Steady-State Stellarators // Problems of Atomic Science and Technology. Series «Plasma Physics». 2016, № 6 (106), p. 56-59.

4. A.V. Lozin, M.M. Kozulia, V.B. Korovin, et al. Wall conditioning discharges driven by $\mathrm{T}$-shaped antenna in Uragan-2M // Problems of Atomic Science and Technology. Series «Plasma Physics». 2018, № 6 (118), p. 50-53.

5. V.E. Moiseenko, Yu.S. Stadnik, A.I. Lyssoivan, V.B. Korovin. Self-Consistent Modeling of RadioFrequency Plasma Generation in Stellarators // Plasma Physics Reports. 2013, v. 39, № 11, p. 873-881.

6. T. Wauters, A. Lyssoivan, D. Douai, et al. OD model of magnetized hydrogen-helium wall conditioning plasmas // Plasma Phys. Control. Fusion. 2011, v. 53, № 12, p. 125003.

7. T Wauters, J Buermans, R Haelterman, et al. RF plasma simulations using the TOMATOR 1D code: a case study for TCV helium ECRH plasmas // Plasma Physics and Controlled Fusion. 2020, v. 62, № 10, p. 105010.

8. Yu.S. Kulyk, V.E. Moiseenko, T. Wauters, A.I. Lyssoivan. A Numerical Model of Radio-Frequency Wall Conditioning for Steady-State Stellarators // Problems of Atomic Science and Technology. Series «Plasma Physics». 2018, № 6 (118), p. 46-49.

9. V.E. Moiseenko, A.A. Beletskii, A.M. Shapoval, et al. A scenario of pulsed ECRH wall conditioning in hydrogenfor the Wendelstein 7-X helias // Problems of Atomic Science and Technology. Series "Plasma Physics». 2019, № 1 (25), p. 37-40.

Article received 27.12.2020

\section{МОДЕЛИРОВАНИЕ ВЫСОКОЧАСТОТНОГО КОРОТКОИМПУЛЬСНОГО РАЗРЯДА В СТЕЛЛАРАТОРЕ}

\section{Ю.С. Кулик, В.Е. Моисеенко, T. Wauters, A.I. Lyssoivan}

Приведены результаты численного моделирования короткоимпульсного разряда для электронноциклотронного нагрева плазмы. Анализ проведен с использованием самосогласованной модели, моделирующей высокочастотное (ВЧ) создание плазмы в установках стеллараторного типа в ионноциклотронном и электронно-циклотронном диапазонах частот. Приведено обсуждение результатов расчетов.

\section{МОДЕЛЮВАННЯ ВИСОКОЧАСТОТНОГО КОРОТКОІМПУЛЬСНОГО РОЗРЯДУ В СТЕЛАРАТОРІ}

\section{Ю.С. Кулик, В.С. Моісеєнко, T. Wauters, A.I. Lyssoivan}

\footnotetext{
Представлено результати чисельного моделювання короткоімпульсного розряду для електронноциклотронного нагріву плазми. Аналіз проведено з використанням самоузгодженої моделі, що моделює високочастотне (ВЧ) створення плазми в установках стелараторного типу в іонно-циклотронному та електронно-циклотронному діапазонах частот. Представлено обговорення результатів розрахунків.
} 